\title{
BREVE HISTÓRIA DA AUTOTRADUÇÃO: OS CASOS DE ANDRÉ BRINK E JOÃO UBALDO RIBEIRO ${ }^{1}$
}

\author{
Maria Alice G. Antunes
}

\section{Introdução}

Em “As pesquisas historiográficas em tradução” (2001) Adriana Pagano escreve que "o campo da historiografia da tradução constitui uma área incipiente [...] como é os Estudos da Tradução" (p. 117). Mauri Furlan (2001) também aponta para o fato de que "a tradutologia ainda está se articulando para a constituição de uma história do pensamento sobre a tradução" (p. 11). Por sua vez, a história da autotradução — a tradução de um texto pelo próprio autor - é praticamente inexistente. Sobre a autotradução, Jan Walsh Hokenson e Marcella Munson afirmam que "os autotradutores foram ignorados pela história da literatura e pela teoria da tradução por longo tempo" (2007: 1). Neste artigo pretendemos contribuir para a construção de um registro de fatos, apresentando características de dois casos de autotradução ainda pouco conhecidos por pesquisadores do tema: o caso do escritor sul-africano André Brink (Ehrlich, 2007) e o do brasileiro João Ubaldo Ribeiro (Antunes, 2009). Destacamos que não é nosso objetivo aqui comparar estratégias e técnicas usadas pelos dois autotradutores. Reconhecemos que uma historiografia das práticas utilizadas por autores que traduziram (ou que traduzem) as próprias obras é necessária, mas está fora do escopo deste trabalho, que se preocupa, inicialmente, com a descoberta e descrição mais geral de casos ainda pouco conhecidos.

Ressaltamos que a quase inexistência de pesquisas historiográficas em autotradução nos força, inicialmente, à construção de "um registro de fatos" (Pagano, 2001: 127) e nos distancia, em princípio, de uma análise profunda do contexto sóciohistórico em que a atividade está inserida. Entretanto, ainda que estejamos, no

\footnotetext{
${ }^{1}$ Parte deste texto foi apresentada no X Encontro Nacional de Tradução e IV Encontro Internacional de Tradução, realizado em Ouro Preto, em setembro de 2009.
} 
momento, preocupados com o levantamento de dados, acreditamos que não é possível apresentar um relato isento de considerações acerca do contexto sócio-histórico em que a autotradução tem se inserido. Pelo contrário, os dados discutidos aqui demonstrarão que o contexto é um agente fundamental. Não cremos tampouco que o sujeito que trabalha na construção de "um registro de fatos" é um mero observador, pois "não há como separar o sujeito do objeto, $[\ldots]$; o que ocorre é uma profunda interação entre sujeito e objeto, inevitavelmente influenciada pelo sistema de valores do primeiro" (Martins, 1996: 40).

Este trabalho está dividido em três partes. Na primeira, apresentaremos um resumo da história da autotradução desde Flavius Josephus (século I) até o século XIX mostrando as considerações de Julio Cesar Santoyo (2002: 27-32), Helena Tanqueiro (2002) e Jan Walsh Hokeson e Marcella Munson (2007) sobre o tema. Em seguida, apresentaremos um registro dos autotradutores dos séculos XX e XXI. Destacaremos o trabalho de André Brink, tradutor das próprias obras do africâner ${ }^{2}$ para o inglês, e o do brasileiro João Ubaldo Ribeiro, tradutor de Sargento Getúlio (1971) e Viva o Povo Brasileiro (1984) também para o inglês. Mostraremos as particularidades de cada caso para demonstrar como a autotradução é uma atividade exercida de maneiras distintas que dependem de forma direta, por exemplo, do autor que realiza a tradução.

\section{A autotradução até o século XIX}

Segundo Tanqueiro (2002), autora da tese "Autotradução: autoridade, privilégio e modelo", Flavius Josephus, o primeiro autotradutor, escreveu em aramaico e traduziu para o grego sua narrativa sobre a destruição de Jerusalém e do Templo pelos romanos no século I (p. 38). Ao traduzir, Josephus pretendia, aparentemente, difundir a informação, pois “o grego era a língua mais usada no Império” (p. 38). Santoyo (2002) apresenta nomes de autores judeus, ingleses e catalães que traduziram seus próprios textos durante a Idade Média (p. 28). Nesse relato uma característica se destaca: esses

\footnotetext{
${ }^{2}$ Uma das línguas oficiais da África do Sul, cuja origem é o holandês do século XVII; apresenta influências do francês e do inglês do período da colonização, assim como do malaio-português e de outras como o hotentote e o boxímane (Dicionário eletrônico Houaiss da Língua Portuguesa).
} 
textos têm em comum o fato de serem textos técnicos ${ }^{3}$. Entre eles, vemos tratados sobre matemática e religião.

Santoyo afirma que a autotradução foi frequente no século XV na península ibérica (2002: 28). Segundo o pesquisador, a atividade explodiu, especialmente na tradução do latim para as línguas vernáculas, nos séculos XVI e XVII (p. 29). Ele descreve como o continente europeu encheu-se de textos únicos no final da Idade Média e durante o Renascimento: uma mesma obra, escritas em duas línguas distintas, pelo mesmo autor (p. 29). Hokeson e Munson (2007) também relatam que "a tradição do autor bilíngue [...] é rica [...], nasceu na antiguidade greco-romana e floresceu na Idade Média e no Renascimento europeus" (p. 1) e que era prática comum no ambiente multilíngue europeu entre o fim dos séculos XV e XVIII, quando os autores traduziam os próprios textos do latim para as línguas vernáculas (p. 1).

As pesquisadoras apontam que a atividade foi prática constante entre colonizadores que traduziam textos europeus para os povos colonizados da Ásia e das Américas (2007: 1). Observam ainda que guerras e deportações fizeram com que escritores adotassem novas línguas de escrita e que muitos escritores pós-coloniais desafiaram a assimetria entre a língua nativa e a língua da colônia escrevendo em duas línguas e traduzindo para ambas (p. 1). As afirmações de Santoyo, Hokeson e Munson contrariam uma informação apresentada com frequência em diversas fontes, que tendem a classificar a autotradução como uma prática pouco comum, restrita a um determinado período.

Além disso, a lista de autotradutores apresentada por Santoyo (2002) sugere que não temos até hoje um registro confiável de autores que traduziam as próprias obras. Não podemos negar, portanto, que o referido artigo, que demonstra que o número de autotradutores e autotraduções é bastante grande, é um material importante como ponto de partida para uma pesquisa historiográfica sobre a autotradução. Entretanto, uma pesquisa mais profunda será necessária para que entendamos como a prática da autotradução foi exercida. Consideramos que ainda são poucos os estudos sobre a autotradução e, muitas vezes, as questões acerca do assunto tendem a repetir o foco na

\footnotetext{
${ }^{3}$ Refiro-me aqui, de forma restrita, aos textos que não "cabem" dentro de um gênero (narrativo, lírico, dramático) ou modo (épico, bucólico, trágico, cômico, satírico) literário.
} 
individualidade do autor de ambos os textos — original e tradução —, deixando de lado, por exemplo, pressões de natureza sistêmica (Filippakopoulou, 2002: 24-25).

Após relatarmos rapidamente como a autotradução foi uma atividade frequente desde o século I até os séculos XVIII e XIX, pretendemos apresentar um relato acerca da autotradução desde o século XX até os dias atuais.

\section{A autotradução nos séculos XX e XXI}

Santoyo (2002) afirma que "a autotradução não é característica da configuração lingüística e cultural da Europa do Renascimento, mas sim característica, em pleno séculos XX e XXI, de Canadá e Estados Unidos, da Índia, Espanha, Rússia e África do

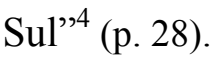

O estudioso cita nomes de autores contemporâneos que traduziram suas próprias obras, entre eles Vladimir Nabokov e Samuel Beckett, que são também aqueles que têm merecido maior atenção de acadêmicos interessados no tema. Entre os autotradutores contemporâneos citados por Santoyo estão ainda Cabrera Infante, Julien Green, Elsa Triolet, Nancy Huston, Rabindranath Tagore, Joseph Brodsky (2002: 29-30). Da lista de Santoyo ficam de fora Milan Kundera, apontado por Lawrence Venuti (2002) e Tanqueiro (2002) como autotradutor, o brasileiro João Ubaldo Ribeiro (Milton, 1995 e 1999; Antunes, 2009), assim como o belga Roger Avermaete (Baker, 1998), o escocês Aonghas MacNeacail (Whyte, 2002: 67), a porto-riquenha Rosario Ferré (Hokenson e Munson, 2006: 200) e o sul-africano André Brink (Ehrlich, 2007), entre outros. Em outras palavras, o já extenso registro pode crescer. Observamos que os autotradutores podem ser divididos em três grupos. No primeiro, incluímos autores vistos como canônicos em seus polissistemas literários de origem e no estrangeiro, tais como Joseph Brodsky, Samuel Beckett, Vladimir Nabokov e Milan Kundera. No segundo grupo, incluímos autores vistos como canônicos em seus polissistemas de origem, mas que não alcançaram o mesmo impacto no polissistema estrangeiro. Entre eles estão Cabrera Infante, Rosario Ferré, André Brink e o brasileiro João Ubaldo Ribeiro. No terceiro grupo, incluímos autores que vivem em locais que apresentam questões políticogeográficas de tensão, tais como os escritores catalães, escoceses e sul-africanos. Consideramos, contudo, que os autotradutores podem ser caracterizados por um

\footnotetext{
${ }^{4}$ Minha tradução do original em catalão.
} 
objetivo comum: o de atingir um número significativo de leitores fora de seus países de origem. João Ubaldo (1990) comenta em artigo sobre o trabalho de autotradução que ele só aceitou o "desafio" porque isso permitiria o alcance de um vasto público-leitor que ele não poderia atingir se sua obra não fosse (auto)traduzida (p. 4). Por outro lado, André Brink viu a autotradução como a única possibilidade de ver seu romance Looking on Darkness (1976) atingir algum público-leitor, depois de proibido na África do Sul. Mas, vejamos como a autotradução vem acontecendo nos séculos XX e XXI. Destacaremos aqui os casos dos escritores André Brink e João Ubaldo Ribeiro.

\section{O caso de André Brink (1935 - )}

Em dissertação apresentada na Universidade de Bar-Ilan, Shlomit Ehrlich (2007) discute o status e a produção dos textos autotraduzidos. O pesquisador escolheu dois romances: Kringe in ' $n$ Bos (1984) / Circles in a forest (1984) e Kennis van die Aand (1973) / Looking on Darkness (1974). O primeiro foi escrito em africâner por Dalene Matthee e traduzido para o inglês pela própria autora. O segunto foi escrito também em africâner por André Brink e traduzido para o inglês pelo próprio autor. Restringiremos nosso relato ao caso de André Brink por considerá-lo interessante sob o ponto de vista da influência que o contexto sócio-histórico pode exercer sobre a autotradução.

A África do Sul tem, atualmente, onze línguas oficiais, entre elas o inglês e o africâner. Entretanto, apenas os dois idiomas - o inglês e o africâner — foram considerados oficiais na África do Sul entre 1925 e 1994. Além de língua oficial, o africâner foi o idioma utilizado por escritores do movimento literário Die Sestigers (The Sixty-ers), tais como André Brink e Breyten Breytenbach (figuras tidas como centrais desse movimento), em uma escrita considerada de oposição ao regime Apartheid.

Em 1973, André Brink publicou o romance Kennis van die Aand. A publicação representou um marco em sua carreira, já que foi a primeira obra literária banida na África do Sul em 1974 (Herlitzius, 2005: 21), já que condenava explicitamente o regime Apartheid além de descrever um relacionamento amoroso inter-racial, um tipo de relacionamento proibido na África do Sul da época. Tal decisão fez com que o autor a traduzisse para o inglês, que se tornasse um escritor conhecido no cenário literário internacional $^{5}$ e um dos escritores conhecidos internacionalmente como "anti-

\footnotetext{
${ }^{5}$ v. http://biography.jrank.org/pages/4180/Brink-Andr-Philippus.html.
} 
Apartheid" (Herlitzius, 2005: 11). Looking on Darkness foi também o primeiro romance africâner a alcançar reconhecimento literário fora de seu país de origem. É importante apontar que o lançamento da obra em inglês permitiu não só que o público-leitor inglês e o norte-americano tivessem acesso ao romance, mas também o público-leitor sulafricano que não utiliza o africâner (ainda que a obra autotraduzida tivesse sido banida no país em 1974). Destacamos ainda que André Brink repetiu o percurso de escritores para quem a autotradução representou uma etapa do processo que lhe garantiu "acesso à visibilidade e à existência literárias" (Casanova, 2002: 171), ainda que as etapas posteriores mais comuns nesse percurso - a tradução em colaboração e a adoção de uma outra língua — não tenham sido seguidas por Brink. O escritor continua morando na África do Sul, escrevendo seus textos em africâner e traduzindo-os para o inglês (Ehrlich, 2007: 18). De qualquer forma, ressaltamos que a tradução do próprio original para uma língua vista como hegemônica tem exercido um papel decisivo para o acesso à visibilidade almejada por escritores provenientes de polissistemas literários nãohegemônicos.

É interessante apontar também que não há qualquer registro no livro Looking on Darkness de que a obra em inglês seja uma tradução e tampouco de que a obra foi traduzida pelo próprio autor. Como afirma Ehrlich (2007), são os sites que dão publicidade ao livro que informam leitores que o romance é uma autotradução. Como veremos em seguida, a omissão da informação foi comum no caso de escritores que traduziram os próprios romances. Sergeant Getúlio (1978), por exemplo, repete as características do caso de Looking on Darkness (1974). Vejamos agora o caso do brasileiro João Ubaldo Ribeiro.

\section{O caso de João Ubaldo Ribeiro (1941 - )}

João Ubaldo Ribeiro verteu dois romances de sua autoria para o inglês Sargento Getúlio (1971) e Viva o Povo Brasileiro (1984). Os motivos que levaram o escritor brasileiro a verter os dois romances são bastante diversos daqueles que motivaram André Brink a fazê-lo. Em "Suffering in Translation” (1990), João Ubaldo declara que a versão de Sargento Getúlio para o inglês se deveu ao fato de que tradutor contratado desistiu da tarefa por causa da dificuldade de compreensão do "sergipês", o dialeto de Getúlio (p. 3). O escritor optou pela autotradução, já que "era jovem e tinha ilusões" (p. 3). Ou seja, ele esperava que a autotradução permitisse seu "acesso à 
visibilidade e à existência literárias" (Casanova, 2002: 171) fora de seu polissistema literário de origem. No mesmo artigo, João Ubaldo (1990) declara que não pretendia repetir a experiência até que seu agente o convenceu a verter Viva o Povo Brasileiro para o inglês usando como argumento a complexidade do romance, cheio de "todos os tipos de "sublínguas"'(p. 3).

Note-se que tal como o caso de Brink, Sergeant Getúlio (1978) não traz nenhuma indicação de o romance em inglês é uma autotradução. Por outro lado, An Invincible Memory traz a incrição translated by the author nas páginas iniciais apontando, a nosso ver, o caráter diferenciado do romance publicado nos Estados Unidos em 1989. Vejamos agora algumas características do processo de publicação dos romances no mercado norte-americano.

Acreditamos que o interesse na publicação de Sargento Getúlio deveu-se em parte ao fato de que o romance publicado em Portugal e na França (em tradução) foi bem recebido pela crítica internacional, como demonstra a capa da publicação nos Estados Unidos que traz a informação de que o romance foi internationally acclaimed. Além disso, Sargento Getúlio é o trabalho de um escritor considerado por leitores profissionais uma das novas vozes literárias brasileiras (Amado, 1978: xi).

Para Heloisa Barbosa (1994), o interesse norte-americano em conhecer e proteger os países da América Latina contra a influência cubana e em promover o crescimento da amizade entre as nações do continente americano através da comunicação intercultural também tem um papel decisivo (p. 61-75). Nos anos 1970, os departamentos de Estudos Latino-Americanos proliferaram nas universidades norteamericanas e o governo financiava pesquisas sobre os países da América Latina (p. 6175). Programas da Association of American University Presses e do Instituto de Estudos Latino-americanos da Universidade de Columbia incentivaram, com o apoio da Fundação Rockefeller e da Fundação Ford, a publicação e distribuição de livros traduzidos (p. 46-47). Consideramos, portanto, que a tradução de Sargento Getúlio para o inglês é motivada pelo mesmo interesse e contexto. Ou seja, a patronagem (v. Lefevere, 1992: 12-25) — institucional, no caso - exerceu papel importante na publicação de Sergeant Getúlio nos Estados Unidos. Vejamos agora o que acontece com Viva o Povo Brasileiro / An Invincible Memory. 
O romance obteve sucesso estrondoso de vendas e de crítica no Brasil, com aproximadamente três milhões de exemplares vendidos até recentemente. ${ }^{6}$ Sobre o romance, Paulo Sergio Pinheiro afirma que é a "obra mais ousada, mais complexa" (1999: 74) do escritor baiano. Já Antonio Risério comenta que "foi com Viva o povo brasileiro que Ubaldo deu um salto espetacular" (1999: 91). Portanto, pode-se afirmar que o duplo sucesso, por assim dizer, foi um fator importante para a publicação nos Estados Unidos. Ratifica-se assim uma das conclusões de Daflon Gomes (2005) em seu estudo sobre a imagem da literatura brasileira refletida por tradução. Para a pesquisadora, o lugar ocupado por um autor em seu polissistema literário de origem é um fator influenciador da seleção para tradução (p. 134).

Finalmente, destacamos que a autotradução não garantiu a João Ubaldo Ribeiro uma "existência literária" fora do Brasil. Como ele mesmo afirma, o país onde seus livros alcançam algum destaque é a Alemanha (Cadernos de Literatura Brasileira, 1999: 41). Entre as possíveis explicações para tal destaque, podemos citar: o fato de que o escritor viveu em Berlin por 15 meses no ano de 1990 a convite da Deutsch Akademischer Austauschdienst; a publicação de crônicas semanais no jornal Frankfurter Rundschau; a produção de peças radiofônicas de grande alcance popular, entre elas, uma adaptação de seu conto "O santo que não acreditava em Deus"; a participação, em 1994, da Feira do Livro de Frankfurt, na Alemanha, onde recebeu o Prêmio Anna Seghers, concedido somente a escritores alemães e latino-americanos; o recebimento de um outro prêmio Die Blaue Brillenschlange - concedido ao melhor livro infanto-juvenil sobre minorias não-européias — pela edição alemã de "Vida e paixão de Pandonar, o cruel"; e, finalmente, a cátedra de Poetik Dozentur na Universidade de Tübigen. Na verdade, a autotradução garantiu ao escritor João Ubaldo Ribeiro um respeito ainda maior dentro das fronteiras do seu polissistema literário de origem.

\section{Considerações finais}

Como pudemos constatar, a autotradução é uma atividade frequente nos países em que há mais de uma língua oficial. Assim, a Espanha, a Escócia e outros países como a Índia, o Canadá e a África do Sul, por exemplo, são locais em que

\footnotetext{
${ }^{6}$ Fonte: Valéria dos Santos, secretária do escritor na Nova Fronteira (email, 24/11/2006).
} 
possivelmente muitos autores, além daqueles que já conhecemos, fazem da tradução de seus originais uma atividade constante. Julgamos importante ressaltar que não consideramos possível (e nem deve ser esse o objetivo de uma pesquisa histórica) chegar a um registro que inclua todos os fatos. Contudo, o acúmulo de estudos de caso vai permitir que práticas de autotradução sejam comparadas e que a autotradução seja conhecida em maior profundidade.

Acreditamos que para compreendermos melhor a autotradução precisaremos de estudos de caso que focalizem autores específicos e examinem as estratégias e técnicas de tradução empregadas por esses autores, o contexto em que os autores e obras estão inseridos e a influência que o contexto exerce sobre esses autotradutores. Tal exame poderá responder, por exemplo, se o autotradutor prefere sinalizar a presença de suas tradições e costumes no texto traduzido ou apagar sua própria cultura na tentativa de uma comunicação mais fácil com o leitor a quem a obra traduzida se destina. $\mathrm{O}$ cotejo entre o texto original e o texto traduzido permitirá também a investigação acerca do papel do autor quando traduz. Exercerá ele, na maioria das vezes, o papel do autor inserindo modificações costumeiramente negadas ao tradutor? Ou o autor exercerá o papel de tradutor, afirmando a autoridade do texto em detrimento de sua própria autoridade sobre o original?

Cremos que há também a necessidade de uma investigação acerca do lugar ocupado pelas obras autotraduzidas nos polissistemas literários estrangeiros. Como vimos anteriormente, o romance de André Brink não traz a indicação de que a obra é uma tradução. Na verdade, a falta de uma indicação sugere que a obra é, na verdade, um original escrito em inglês. No caso de João Ubaldo, os procedimentos diferem. Tal situação reflete a pouca clareza em relação ao objeto.

Constatamos ainda que este estudo sobre a autotradução demonstra que esta não é uma atividade que se dê de forma homogênea, por assim dizer. Acreditamos que os casos de André Brink e João Ubaldo Ribeiro, entre outros, apresentam muitas particularidades que impedem generalizações absolutas sobre o tema. O papel do contexto, por exemplo, tem características distintas. No caso de Brink, é o contexto sócio-histórico que determina a publicação em inglês (já que o romance escrito originalmente em africâner havia sido banido) e, consequentemente, a autotradução. Já no caso de João Ubaldo o contexto apenas favorece a publicação e, consequentemente, a autotradução. 


\section{Referências bibliográficas}

AMADO, J. Introduction. In: RIBEIRO, J. U. Sergeant Getúlio. Boston: Houghton Mifflin Company, 1978.

ANTUNES, M.A.G. O Respeito pelo Original. João Ubaldo Ribeiro e a Tradução. São Paulo: Annablume, 2009.

BAKER, M. (Ed.) Routledge Encyclopedia of Translation Studies. 1. ed. London: Routledge, 1998.

BARBOSA, H. The virtual image: Brazilian literature in English translation. Coventry, UK, 1994. Tese (Doutorado) - Centre for Translation and Comparative Cultural Studies, University of Warwick.

CADERNOS DE LITERATURA BRASILEIRA: João Ubaldo Ribeiro. São Paulo: Instituto Moreira Salles, 1999.

CASANOVA, P. A República Mundial das Letras. Tradução por Marina Appenzeller. São Paulo: Estação liberdade, 2002.

DAFLON GOMES, M. L. Identidades refletidas. Um estudo sobre a imagem da literatura brasileira refletida por tradução. Rio de Janeiro, 2005. Dissertação (Mestrado) - Programa de Pós-Graduação em Letras, PUC-Rio.

EHRLICH, S. The status and production of self-translated texts: Afrikaans-English as a case in point. Jerusalém, 2007. Dissertação (Mestrado) - Bar-Ilan University.

FURLAN, M. Brevíssima história da teoria da tradução no Ocidente: I - Os Romanos. Cadernos de Tradução, Florianópolis: NUT, v. 2. 8, p. 11-28, 2001.

HERLITZIUS, E.M. A comparative analysis of the South African and German reception of Nadine Gordimer's, André Brink's and J. M. Coetzee's works. Londres: Transaction Publishers, 2005.

HOKESON, J. e MUNSON, M. The Bilingual Text. History and Theory of Literary Self-translation. Manchester: St. Jerome Publishing, 2007.

MARTINS, M.A.P. As relações nada perigosas entre História, Filosofia e Tradução. Cadernos de Tradução, Florianópolis: NUT, v. 1, p. 37-51, 1996.

MILTON, J. Will Self-Translation Reflect the Translator's Culture? João Ubaldo's Translation of His Own Novel Viva o povo brasileiro. Comunicação apresentada no VIII CATS - Canadian Association for Translation Studies Congress, Université du Quebéc à Montréal, Canadá, 1995 (texto inédito).

Translating Latin America. In: MARTINS, M.A.P. (org.) Tradução e Multidisciplinaridade. Rio de Janeiro: Lucerna, p. 167-173, 1999. 
PAGANO, A. As pesquisas historiográficas em tradução. In: PAGANO, Adriana (Org.) Metodologia de Pesquisa em Tradução, Estudos Lingüísticos 3, Belo Horizonte: Faculdade de Letras, p. 117-146, 2001.

PINHEIRO, P. C. Povo e dominação. In: Cadernos de literatura brasileira: João Ubaldo Ribeiro. São Paulo: Instituto Moreira Salles, pp. 74-90, 1999.

RIBEIRO, J. U. Suffering in translation. In: P.T.G. Newsletter, Portuguese Translation Group (ATA, New York) 3, 1990, jan/fev, p. 3-4. . Sargento Getúlio. Rio de Janeiro: Nova Fronteira, 1971. . Sergeant Getúlio. Boston: Houghton Mifflin Company, 1978. . Viva o povo brasileiro. Rio de Janeiro: Nova Fronteira, 1984. . An invincible memory. Nova York: Harper \& Row Publishers, 1989.

RISÉRIO, A. Viva Ubaldo brasileiro. In: Cadernos de literatura brasileira: João Ubaldo Ribeiro. São Paulo: Instituto Moreira Salles, p. 91-102, 1999.

SANTOYO, J. C. Traducciones de autor: Una mirada retrospectiva. Quimera 210, p. 27-32, 2002.

TANQUEIRO, H. Autotradução: Autoridade, privilégio e modelo. Barcelona, 2002. Tese (Doutorado) - Departament de Traducció i d'Interpretació, Universidad Autónoma de Barcelona.

VENUTI, L. Escândalos da tradução: por uma ética da diferença. Tradução por Laureano Pelegrin, Lucinéia Marcelino Villela, Marileide Dias Esqueda e Valéria Biondo. 1. ed. Bauru: EDUSC, 2002.

WHYTE, C. Against self-translation. Translation \& literature, Edinburgh, v. 11, p. 64-70, 2002. 